\title{
Study of tropospheric scintillation effects in Ku-band frequency for satellite communication system
}

\author{
Nadirah Abdul Rahim, Hanis Nabilah A. Mulop, Khairayu Badron \\ Department of Electrical and Computer Engineering, International Islamic University Malaysia, Malaysia
}

\begin{tabular}{l} 
Article Info \\
\hline Article history: \\
Received Jul 22, 2019 \\
Revised Dec 7, 2019 \\
Accepted Dec 15, 2019 \\
\hline
\end{tabular}

\section{Keywords:}

$\mathrm{CDF}$

Ku-band

Satellite communication system

Scintillation models

Tropospheric scintillation

\begin{abstract}
Scintillation is a rapid fluctuation of electromagnetic waves in terms of phase and amplitude due to a small-scale inconsistency in the transmission path (or paths) with time. Scintillation exists continuously throughout a day whether during raining or clear sky conditions. The raw signal data need to exclude other propagations factors that include signal fluctuations to further understand the scintillation studies. This paper presents the analysis of tropospheric scintillation data from January 2016 till December 2016 at Ku-band frequency of $12.202 \mathrm{GHz}$ beacon signal. The experimental data from MEASAT 3B were collected and analyzed to see the effect of tropospheric scintillation. The elevation angle of the dish antenna is $77.45^{\circ}$. The highlighted objectives are to analyze the scintillation data at Ku-band, and to compare and validate the results with other scintillation models. The result shows that the stipulated scintillation analysis has higher amplitude, which is $0.73 \mathrm{~dB}$ compared to other scintillation analysis which has lower scintillation amplitude: $0.45 \mathrm{~dB}$ (Karasawa), $0.42 \mathrm{~dB}$ (ITU-R), $0.4 \mathrm{~dB}$ (Nadirah \& Rafiqul), $0.42 \mathrm{~dB}$ (Van De Kamp), and $0.11 \mathrm{~dB}$ (Anthony \& Mandeep).
\end{abstract}

Copyright $\odot 2020$ Institute of Advanced Engineering and Science. All rights reserved.

\section{Corresponding Author:}

Nadirah Abdul Rahim

Department of Electrical and Computer Engineering,

International Islamic University Malaysia,

Jalan Gombak 53100 Kuala Lumpur.

Email: nadirahabdulrahim@iium.edu.my

\section{INTRODUCTION}

Satellite is the main element in most of telecommunication system around the globe. Data information are exchanged and received in various forms by earth stations that are transmitted by a microwave repeater station or also known as communications satellite [1]. The significance of communication satellite is that it is basically utilized for the business and government services purposes such as data transfer services, voice services and etc. The communication satellite is also used for obtaining the corporate assets, sending emails, browse internet and it can likewise be utilized to communicate through a high quality voice compression without taking into account the location around the world [2].

There are several propagation effects which are caused by the tropospheric layer: attenuation due to rain, depolarization, gas absorption and scintillation caused by the atmospheric turbulence [3]. Although in the communication systems, rain has the main impact, scintillation now has become crucial for low-margin systems at high frequencies and low elevation angles [3]. Improperly titled paper may never reach the audience for which it was intended, so be specific. The tropospheric scintillation effects are important to be observed especially in broadcasting and telecommunication services which use the Ku-band frequency in the satellite communication links [4].

Scintillation is one of the events which lead to signal degradation through the earth's atmosphere. There are two types of scintillations: ionospheric scintillation and tropospheric scintillation [2]. This paper 
emphasizes on tropospheric scintillation because the frequency focused here is at Ku-band in tropical climate. Several scintillation models have been developed and studied by other researchers in the past, however most of the models can only be used in the four seasons (winter, spring, summer and autumn) countries and cannot be applied in the tropical countries such as Malaysia, Singapore, Thailand, Brazil, and etc. Furthermore, previous scintillation studies' data were collected from non-tropical countries such as US, Finland, Germany, United Kingdom and many more. Hence, the scintillation models cannot be used in tropical countries due to the different pattern of climate compared to the four-season countries. The tropical countries consist of high humidity, uniform temperature and heavy rainfall. There are only a few research activities conducted on scintillation in tropical countries and data collected in Malaysia does not fit with any existing models [5-13]. The scintillation models must be evaluated based on the tropical countries data collection and measurement. The scintillation data for tropical climate countries are very limited typically for high elevation angle. Therefore, it is very important to study the scintillation effects based on the data measured in the tropical countries.

\section{LITERATURE REVIEW}

Scintillation can be found in ionosphere and troposphere layers. In the ionosphere layer, the irregularities of electron that affect frequencies up to $6 \mathrm{GHz}$ are called ionospheric scintillation. Whereas, the scintillations which affect the troposphere layer for the frequencies band above $3 \mathrm{GHz}$ due to the refractive index irregularities is called tropospheric scintillation. The research aim is to study the tropospheric scintillation which affects the Ku-band. This type of scintillation is also caused by temperature inversion layers and high humidity gradients [4]. With the variety of local climate, the impact of tropospheric is seasonally dependent. The structure of the refractive index in the troposphere can be regarded horizontally layered. Furthermore, with the change in altitude, the variations seem to be appeared as thin layers [4]. Moreover, scintillation conditions affect more significantly to slant path at low elevation angle which is highly slanted to the layer formation. The troposphere common properties of the refractive index are widely known. The index of refraction or the atmospheric radio refractive index, $\mathrm{n}$, is a function of pressure, water vapour content, and temperature [4]. The features of the refractive index are normally described in terms of $\mathrm{N}$ units, for $\mathrm{n}$ is very close to 1 . It is defined as

$$
N=(n-1) \times 10^{6}=\frac{77.6}{T}\left(p+4810 \frac{e}{T}\right)
$$

where the atmospheric pressure in millibars $(\mathrm{mb})$ is expressed as $p$; Temperature, in degrees $\mathrm{K}$ is $\mathrm{T}$; and e is the water vapour pressure in mb. In (2), the first expression is known as the "dry term"

$$
N_{d r y}=p \frac{77.6}{T}
$$

while the "wet term" is the second expression

$$
N_{w e t}=3.732 \times 10^{5} \frac{e}{T^{2}}
$$

For frequencies up to $100 \mathrm{GHz}$ the accuracy of Equations (2) to (4) are within 0.5\% [4]. The refractivity of the long-term dependence can be represented in an exponential form,

$$
N=315 e^{\frac{-h}{7.36}}
$$

where the altitude, in $\mathrm{km}$ is $h$. This estimation is applicable for altitude up to about $15 \mathrm{~km}$ [14].

\section{RESEARCH METHODOLOGY}

$\mathrm{Ku}$-Band signal was transmitted at $12.202 \mathrm{GHz}$ frequency from the MEASAT $3 \mathrm{~B}$ at longitude (91.5 East) with vertical polarization that provides more than 100 channels which covers Southeast Asia including Malaysia and Indonesia as well as Australia. Table 1 shows the satellite specifications for ASTRO Broadcast Network System. The satellite raw data consists of 12 months period from January 2016 till December 2016 in order to study the scintillation effect. The raw beacon data consist of scintillation, rain and other propagation data. Therefore, in order to separate the scintillation data from other data, a technique is applied by using filtering in MATLAB. Figure 1 illustrates the steps to acquire the scintillation amplitude. Cumulative Distribution Function (CDF) of the scintillation data is obtained by the division of 
the scintillation amplitude into two parts: scintillation fades which is the negative signal amplitude and enhancements which is the positive signal amplitude. Next, the CDF of scintillation fades are calculated monthly and annually. Figure 2 illustrates on how to acquire the monthly and annual cumulative distribution function of scintillation fades.

Table 1. Satellite specifications

\begin{tabular}{ll}
\hline Satellite & MEASAT 3B \\
\hline Site & ASTRO Broadcast Network System, Bukit Jalil, Kuala Lumpur, Malaysia \\
Ground station longitude & 101.70 \\
Ground station latitude & 3.15 \\
Satellite position & $91.517^{\circ} \mathrm{E}$ \\
Elevation angle & $77.45^{\circ}$ \\
Azimuth & $253.02^{\circ}$ \\
Polarization & Vertical \\
Frequency & $12.202 \mathrm{GHz}$ \\
Antenna diameter & $13 \mathrm{~m}$ \\
\hline
\end{tabular}

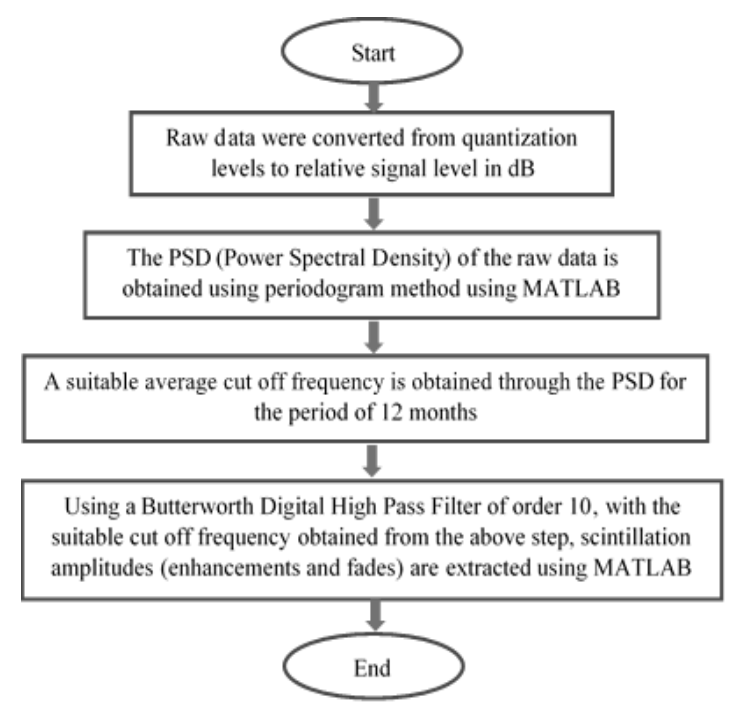

Figure 1. Flowchart of scintillation data extraction from raw data

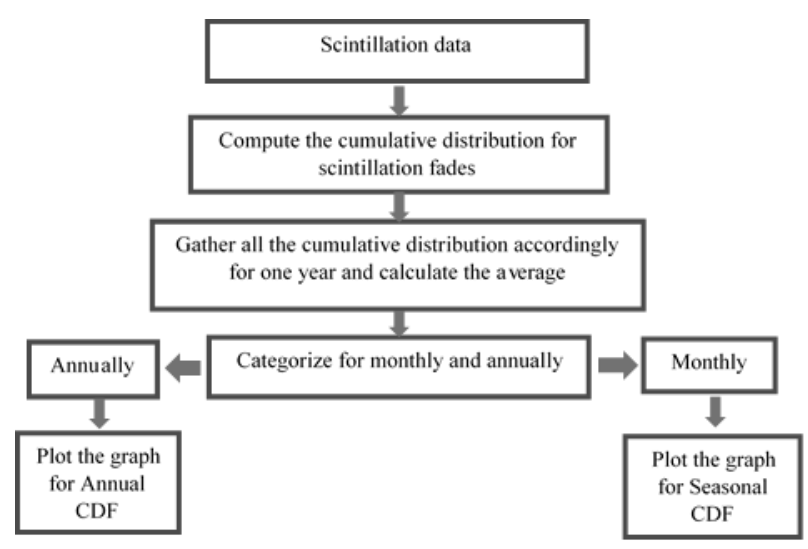

Figure 2. Flowchart to analyze monthly and annual CDF

\section{RESULTS AND ANALYSIS}

Tropospheric scintillation leads to random scintillation fades and scintillation enhancement of the received signal at a lower elevation angles [14]. Majority of the tropospheric scintillation studies that have been focused on low elevation angles and high frequencies due to the fact that scintillation amplitude is highly observed in this case. However, for the case of high elevation angles and high frequencies only a few studies have been done. This research was done on the basis of high elevation angle and high frequency and is similar to the research in [5-13]. The differences between those researches are the location, elevation angle, frequency, the satellite used and the data sampling as tabulated in Table 2. From Table 2, it can be deduced that this paper, has the same elevation angle as in IIUM but is higher than the one from USM. The humidity and the temperature for each research are different due to the distinct locations. Therefore, due to the difference in humidity and temperature, the scintillation effects will vary for each research [15-16].

Table 2. Research comparison in Malaysia

\begin{tabular}{|c|c|c|c|c|c|c|}
\hline Research & Location & $\begin{array}{l}\text { Elevation } \\
\text { Angle }\left({ }^{\circ}\right)\end{array}$ & $\begin{array}{l}\text { Type of Antenna / } \\
\text { Diameter }(\mathrm{m})\end{array}$ & $\begin{array}{l}\text { Frequency } \\
(\mathrm{GHz})\end{array}$ & $\begin{array}{l}\text { Data } \\
\text { Sampling (s) }\end{array}$ & Satellite \\
\hline USM & Penang, Malaysia & 40.1 & Cassegrain Antenna / 2.4 & 12.255 & 1.0 & Superbird C \\
\hline IIUM & $\begin{array}{l}\text { Gombak, Kuala Lumpur, } \\
\text { Malaysia }\end{array}$ & 77.5 & Dish Antenna / 2.4 & 10.982 & 0.1 & MEASAT-3 \\
\hline ASTRO & $\begin{array}{l}\text { Bukit Jalil, Kuala } \\
\text { Lumpur, Malaysia }\end{array}$ & 77.5 & Dish Antenna / 13 & 12.2015 & 0.05 & MEASAT-3B \\
\hline
\end{tabular}




\subsection{Extraction of scintillation data}

In order to eliminate other propagation factors that lead to data fluctuations, the raw measured data need to be studied and processed [17]. This is due to the fact that other propagation factors introduce fluctuations at a lower rate than those caused by scintillation [4]. Therefore, the raw data obtained from ASTRO need to go through a high pass filter with an appropriate cut off frequency to observe the scintillation signal level. The data obtained were already divided into two: rain and clear sky. For the purpose of this research, clear sky data are used to discard any data that contribute to rain attenuation. The raw data obtained were recorded in terms of attenuation in $\mathrm{dB}$; hence, the data need to be subtracted by $75 \mathrm{~dB}$ to obtain the original received signal level. Figure 3 illustrates the received signal level of measured raw data versus number of data for 22 February 2016. The data are usually represented in terms of percentage of time [16] but the number of samples and sampling time vary for each day for the raw data received from ASTRO thus, the data are represented in terms of number of data.

Next, periodogram method with the help from Hanning window was used to acquire the power spectral density ( $\mathrm{dB} / \mathrm{rad} / \mathrm{sample})$ plot of the raw data [18]. Using MATLAB, the average power spectral density plot was obtained with a suitable cut off frequency. The non-scintillation effects will be included if the cut off frequency is set to be too low while the scintillation effects in the received signal level are eliminated if the cut off frequency is set to be too high [16]. Hence, the cut off frequency needs to be cautiously set. Figure 4 depicts the average power spectral density. Based on Figure 4, a flat portion between $0.03 \mathrm{~Hz}$ to $0.1 \mathrm{~Hz}$ is seen and followed by a slope of approximately $\mathrm{f}^{-8 / 3}$ above $0.1 \mathrm{~Hz}$. For fully generated turbulence, the scintillation spectrum has a common pattern of low pass filtered white noise with a $-8 / 3$ slope [9].

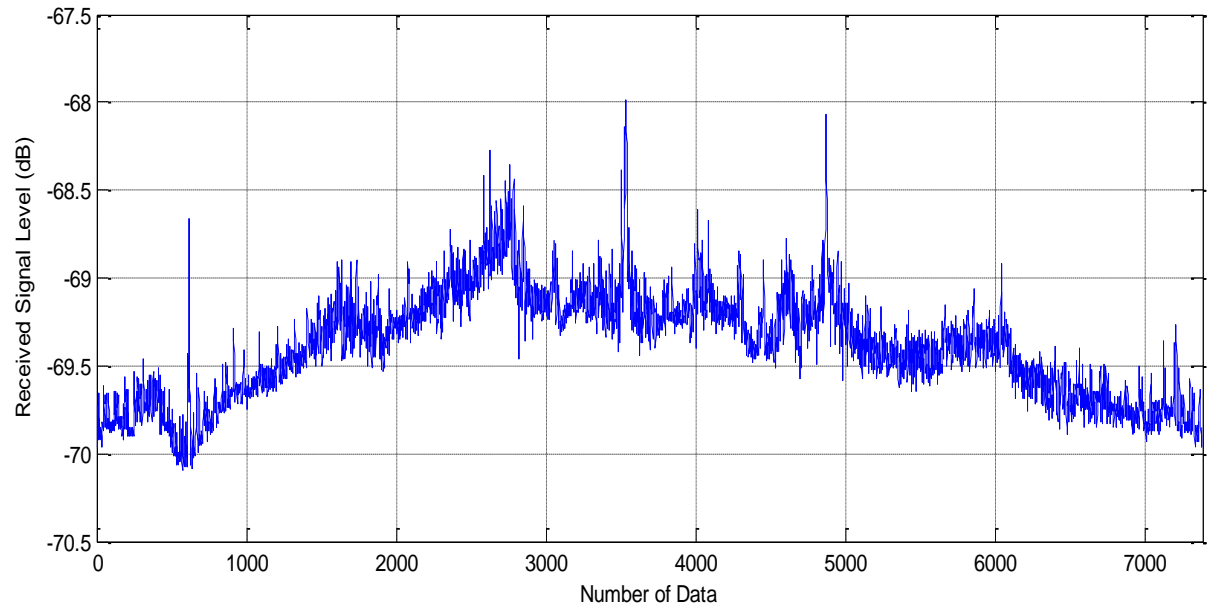

Figure 3. Measured raw data for 22 February 2016

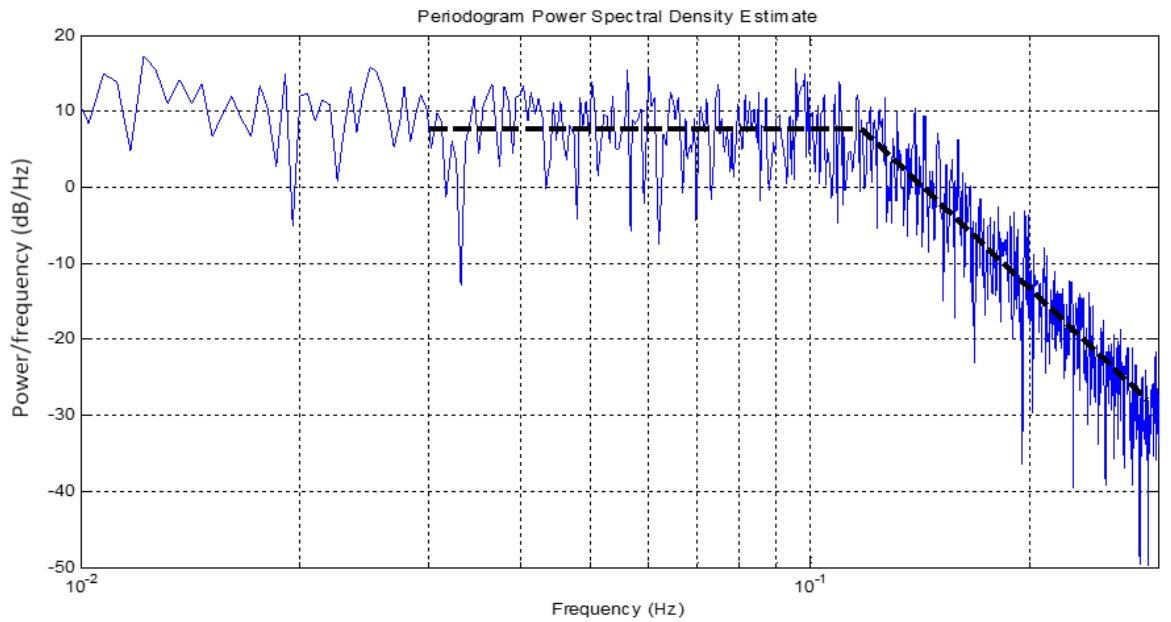

Figure 4. Average power spectral density 


\subsection{Analysis of scintillation data using MATLAB}

Scintillation fades and enhancements were computed by using the cut off frequency of $0.11 \mathrm{~Hz}$ with the aid of high pass filter of order 10 so that the scintillation signals could be observed clearly [7]. The cut off frequency was obtained by calculating the average cut off frequency for the 12 months of year 2016 scintillation data as shown in Table 3. In MATLAB, after going through the filtering process, scintillation amplitudes for each day were displayed. After the scintillation amplitudes were obtained in the MATLAB, the amplitudes were then divided into two: scintillation fades and scintillation enhancements. Scintillation enhancements refer to the positive signal level of the scintillation amplitude whereas scintillation fades refer to the negative signal level of the scintillation amplitude. Scintillation enhancements produce an increase in intermodulation disturbance in a satellite transponder utilized in multicarrier and scintillation fades usually influence the earth station tracking systems, considering the usage of time constant in the system [18]. Figure 5 illustrates the scintillation amplitude for 13 April 2016.

Table 3. Cut off frequencies

\begin{tabular}{|c|c|}
\hline Month & Cut-off Frequency (Hz) \\
\hline January 2016 & 0.11 \\
\hline February 2016 & 0.12 \\
\hline March 2016 & 0.11 \\
\hline April 2016 & 0.12 \\
\hline May 2016 & 0.11 \\
\hline June 2016 & 0.12 \\
\hline July 2016 & 0.12 \\
\hline August 2016 & 0.11 \\
\hline September 2016 & 0.11 \\
\hline October 2016 & 0.11 \\
\hline November 2016 & 0.11 \\
\hline December 2016 & 0.12 \\
\hline
\end{tabular}

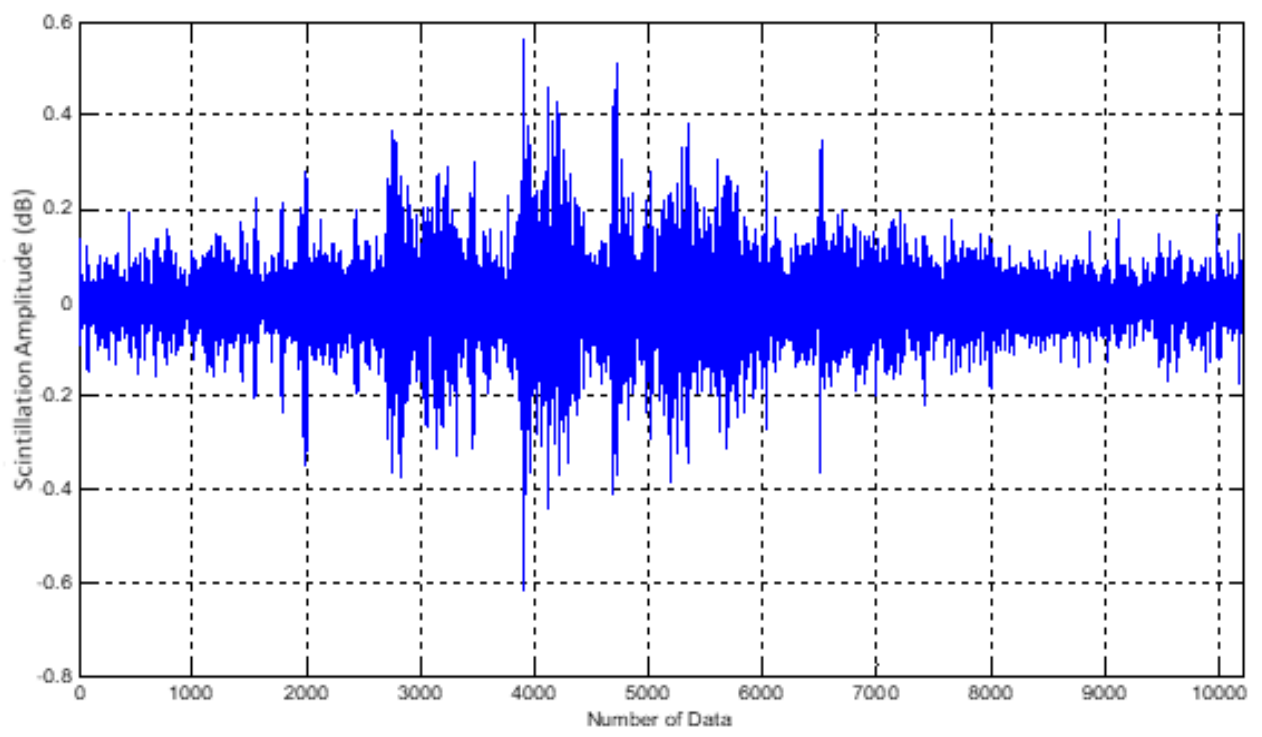

Figure 5. Scintillation amplitude of 13 April 2016

\subsection{Data processing for cumulative distribution function (CDF)}

Scintillation data were categorized into two parts: positive signal levels, scintillation enhancements and the negative signal levels, scintillation fades [19-25]. Then, the cumulative distribution was computed for scintillation fades. Figure 6 depicts the measured cumulative distribution function for scintillation fades on monthly basis. From Figure 6 it can be concluded that the measured scintillation fades in February 2016 are the highest until at $0.3 \%$ of the data, scintillation fades in March exceeded the rest of the months. Moreover, severe fading can be seen in February 2016 at $0.01 \%$ and followed by September 2016. Meanwhile, in November 2016, scintillation fades are the weakest. 


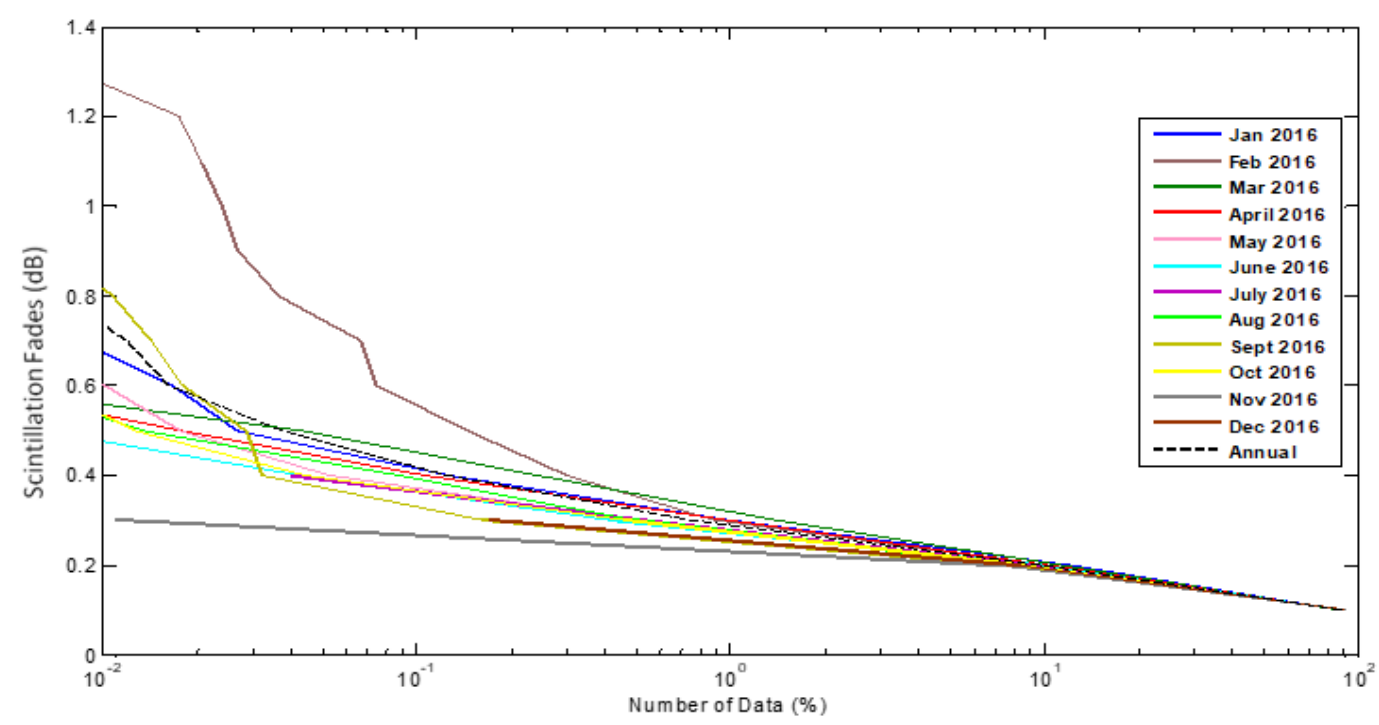

Figure 6. Measured monthly cumulative distribution for scintillation fades

The scintillation fades for all the months in 2016 are merely the same, but those plots branched out at approximately $10 \%$ of the data. In September 2016, the scintillation jumped further up till it reached its maximum at $0.8 \mathrm{~dB}$ and overlapped with scintillation fades in December 2016 at $0.17 \%$. Besides that, the measured average annual cumulative distribution of scintillation fades exceeded the individual month at approximately at $1 \%$ of the data. However, in February 2016, the plot over predicted the average annual plot at every percentage number of data whereas in March 2016, the plot exceeded the average annual plot at $0.03 \%$ of the data. The values of the scintillation fades for each month and the percentage number of data are tabulated in Table 4.

Table 4. Measured monthly distributions of scintillation fades

\begin{tabular}{|c|c|c|c|c|c|c|c|c|c|c|c|c|}
\hline \multirow{2}{*}{$\begin{array}{l}\text { Scintillation } \\
\text { Fades }(\mathrm{dB})\end{array}$} & \multicolumn{12}{|c|}{ Number of Data (\%) } \\
\hline & Jan & Feb & March & April & May & June & July & Aug & Sept & Oct & Nov & Dec \\
\hline 0.1 & 86.5 & 87.88 & 86.7 & 88.5 & 90.2 & 89.8 & 90.2 & 91.1 & 92.07 & 90.7 & 92.6 & 91.4 \\
\hline 0.2 & 12.33 & 10.52 & 11.64 & 10.4 & 9.18 & 9.78 & 9.25 & 8.3 & 7.67 & 8.74 & 7.36 & 8.43 \\
\hline 0.3 & 0.97 & 0.87 & 1.37 & 0.96 & 0.48 & 0.40 & 0.51 & 0.48 & 0.17 & 0.45 & 0.01 & 0.17 \\
\hline 0.4 & 0.13 & 0.3 & 0.24 & 0.11 & 0.05 & 0.04 & 0.04 & 0.087 & 0.03 & 0.04 & & \\
\hline 0.5 & 0.03 & 0.15 & 0.04 & 0.018 & 0.018 & 0.006 & & 0.013 & 0.028 & 0.01 & & \\
\hline 0.6 & 0.02 & 0.075 & 0.0036 & 0.0032 & 0.01 & 0.003 & & 0.0045 & 0.018 & 0.0063 & & \\
\hline 0.7 & 0.008 & 0.067 & & & 0.008 & & & & 0.014 & & & \\
\hline 0.8 & 0.006 & 0.036 & & & 0.005 & & & & 0.01 & & & \\
\hline 0.9 & 0.0021 & 0.027 & & & 0.003 & & & & 0.007 & & & \\
\hline 1.0 & & 0.024 & & & & & & & 0.004 & & & \\
\hline
\end{tabular}

\subsection{Comparison of measured data with the existing scintillation models}

The four models: Karasawa, ITU-R, Van De Kamp, and OTUNG are compared against the measured cumulative distribution. The comparison according to the location, elevation angle, frequency and data sampling are tabulated as in Table 5. All the cumulative distribution of the prediction models were computed using the equations elaborated in the literature review. From Figure 7 it can be deduced that the annual measured plot exceeds the scintillation fades for Karasawa. Similarly, from Figure 7, the scintillation fades for ITU-R is under predicted the annual measured plot at all percentages of time. Next, to compute the scintillation fades for Van de Kamp, cloud information was included. Based on Figure 7, the annual measured plot exceeds the scintillation fades for ITU-R model whereas for OTUNG, the scintillation fades over predicted the annual measured plot. However, at $0.3 \%$, the annual measured plot exceeds the OTUNG scintillation fades plot. For this research study, the measured curve is compared with the other scintillation models to see whether the scintillation amplitude is comparable or not. The future work for this study is that the measured curve is modified according to the chosen scintillation models. 
Table 5. Prediction models comparison

\begin{tabular}{|c|c|c|c|c|c|c|}
\hline Research & Location & $\begin{array}{l}\text { Elevation } \\
\text { Angle }\left(^{\circ}\right)\end{array}$ & $\begin{array}{l}\text { Type of Antenna / } \\
\text { Diameter }(\mathrm{m})\end{array}$ & $\begin{array}{l}\text { Frequency } \\
(\mathrm{GHz})\end{array}$ & $\begin{array}{l}\text { Data } \\
\text { Sampling (s) }\end{array}$ & Satellite \\
\hline Karasawa [21] & Yamaguchi, Japan & $4-30$ & Dish Antenna / 7.6 & 11.452 & 1 & Intelsat-V \\
\hline ITU-R [14] & Global & $>4$ & Dish Antenna / 3-36 & $7-14$ & NA & NA \\
\hline $\begin{array}{l}\text { Van de Kamp } \\
{[22]}\end{array}$ & Global & $3-33$ & Dish Antenna & $7-30$ & 0.05 & $\begin{array}{l}\text { Satellite Links in } \\
\text { Europe, Japan } \\
\text { and US }\end{array}$ \\
\hline OTUNG [17] & Sparsholt, UK & 28.74 & $\begin{array}{l}\text { Diamond Shaped } \\
\text { Antenna / } 1.2\end{array}$ & 19.7704 & 0.1 & Olympus \\
\hline USM [7] & Penang, Malaysia & 40.1 & $\begin{array}{l}\text { Cassegrain Antenna / } \\
2.4\end{array}$ & 12.255 & 1.0 & Superbird C \\
\hline IIUM [11-12] & $\begin{array}{l}\text { Gombak, Kuala } \\
\text { Lumpur, Malaysia }\end{array}$ & 77.5 & Dish Antenna / 2.4 & 10.982 & 0.1 & MEASAT-3 \\
\hline $\begin{array}{l}\text { ASTRO } \\
\text { (Measured) }\end{array}$ & $\begin{array}{l}\text { Bukit Jalil, Kuala } \\
\text { Lumpur, Malaysia }\end{array}$ & 77.5 & Dish Antenna / 13 & 12.202 & 0.05 & MEASAT-3B \\
\hline
\end{tabular}

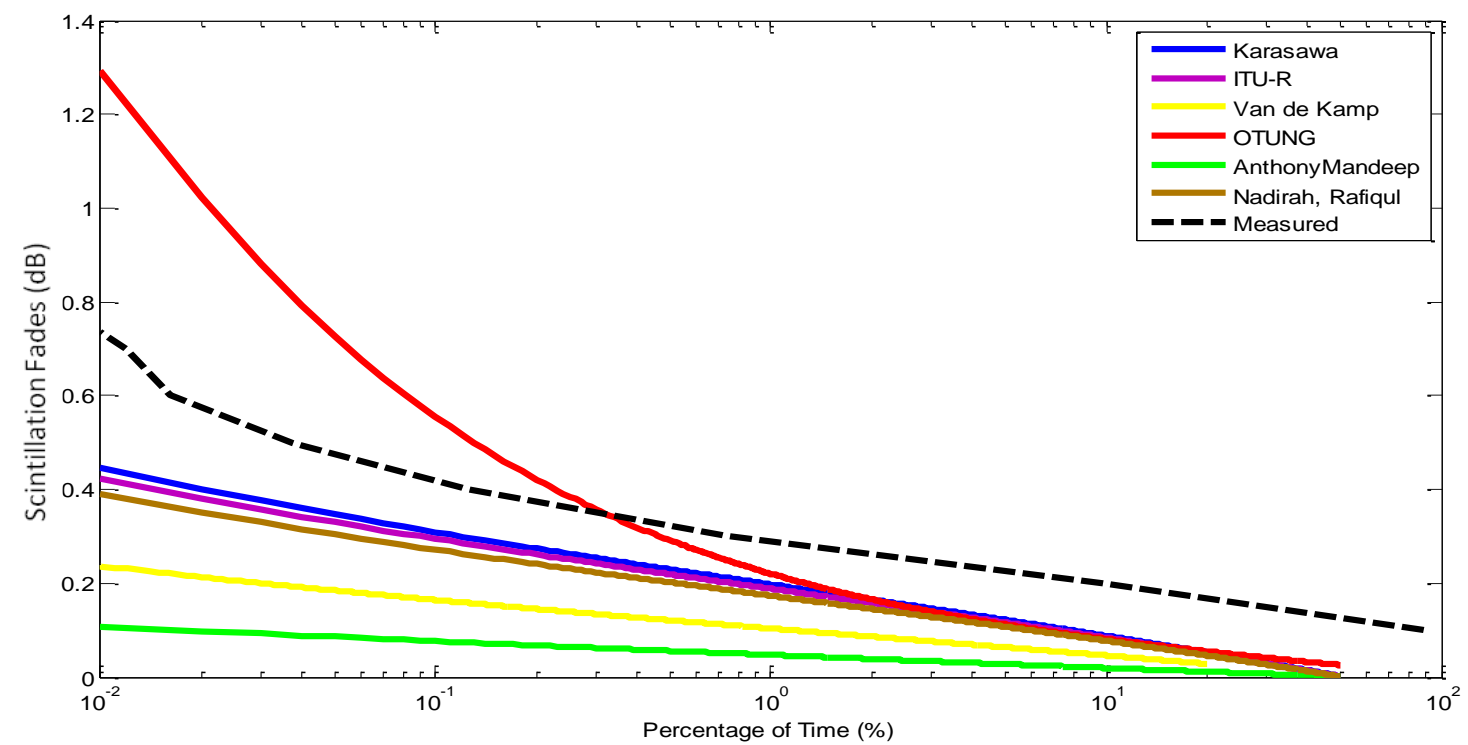

Figure 7. Scintillation fades of prediction model and measured data

\section{CONCLUSION}

In conclusion, the satellite communication study pertaining to the scintillation modeling in $\mathrm{Ku}$-band has been reported and compared with the previous scintillation models. The scintillation effects on high elevation angle and high frequency have been analyzed and discussed. The results of the measured scintillation data from January 2016 till December 2016 are presented in this paper. Data from ASTRO with frequency of $12.202 \mathrm{GHz}$ and elevation angle of $77.5^{\circ}$ were used to observe the scintillation effects in the tropical climate. The raw data were processed in the MATLAB to gain a suitable cut off frequency. Then, the average cut off frequency was used in the high pass filter of order 10 to eliminate any propagation factors that lead to other propagation effects. The scintillation data were then filtered and divided into two: scintillation fades and scintillation enhancements. However, this paper is only focused on the scintillation fades and therefore the data for scintillation enhancements were ignored. The cumulative distributions of scintillation fades were computed based on monthly and annual. Then, the annual cumulative data were compared with the six existing scintillation fades model namely Karasawa, ITU-R, OTUNG, Van de Kamp, Anthony-Mandeep, and Nadirah-Rafiqul.

Based on the finding, the annual measured scintillation fades over predicted all other existing scintillation models which has the highest scintillation fades reading. The scintillation fades at $0.01 \%$ for annual measured data is $0.73 \mathrm{~dB}$ whereas for OTUNG is $0.55 \mathrm{~dB}$, Karasawa is $0.45 \mathrm{~dB}$, ITU-R is $0.42 \mathrm{~dB}$, Nadirah-Rafiqul is $0.4 \mathrm{~dB}$, Van de Kamp is $0.42 \mathrm{~dB}$, and Anthony-Mandeep $0.11 \mathrm{~dB}$. Therefore, the objectives of this research study are met accordingly, which are: to analyze the scintillation data obtained for Ku-band and to compare and validate the results with other scintillation models. 
This research can be improved by analyzing the scintillation enhancements for the measured data and compare it with the existing scintillation enhancements models. It is also recommended to study the monthly, seasonal, diurnal and annual statistics of both scintillation enhancements and scintillation fades. In order to know how reliable, the model is for this measured data, a new scintillation model based on the measured data need to be computed. Therefore, more research activities should be carried out after comparing the annual measured cumulative distribution with the other existing models.

\section{ACKNOWLEDGEMENTS}

The authors would like to express gratitude to MEASAT Satellite System Sdn. Bhd. (MEASAT) for data access and Research Management Centre (RMC) of IIUM for the funding of the research under the grant scheme P-RIGS18-005-0005.

\section{REFERENCES}

[1] B. Elbert, "Introduction to Satellite Communication," Artech House, 2008.

[2] P. Timothy, W. C. Bostian, and J. E. Allnutt, "Satellite Communication," John Wiley and Sons, NJ, 2003.

[3] A. G. M. Akhondi, "New model for tropospheric scintillation fluctuations and intensity in the V-band for the earthsatellite links," The 4th WSEAS International Conference on Electronics, Hardware, Wireless and Optical Communications (EHAC 05) Salzburg, Austria, 2015.

[4] J. Louis, "Satellite Communications Systems Engineering," A John Wiley \& Sons, Ltd, Publications, 2008.

[5] J. S. Mandeep, "Experimental analysis of tropospheric scintillation in Northern Equatorial West Malaysia," International Journal of Physical Sciences, vol. 6, no. 7, pp. 1673-1676, 2011.

[6] J. S. Mandeep, et al., "Experimental analysis on tropospheric amplitude scintillation on a medium antenna elevation angle in Malaysia," Int. J. Comput. Sci. Netw. Secur., vol. 7, no. 2, pp. 264-266, 2007.

[7] M. Singh, J. Singh, S. Idris, S. Hassan, and F. Ain, "Measurement of tropospheric scintillation from satellite beacon at Ku-band in South East Asia," J. Comput. Sci., vol. 7, no. 2, pp. 251-254, 2007.

[8] J. S. Mandeep, A. C. C. Yee, M. Abdullah, and M. T. Islam, "Tropospheric scintillation measurements in Ku-band satellite signals on earth-space paths with low elevation angle," Idojaras, vol. 115, no. 4, pp. 265-273, 2011.

[9] J. S. Mandeep, S. I. S. Hassan, M. F. Ain, and K. Igarashi, "Tropospheric scintillation measurement in Malaysia at Ku-band," J. Electromagn. Waves Appl., vol. 22, no. 8-9, pp. 1063-1070, 2008.

[10] I.F. Elshami, J. Din, L.H. Yin, and A.I. Elgayar, "Characterization of concurrent Ku-band tropospheric scintillation and rain attenuation in Malaysia," Indonesian Journal of Electrical Engineering and Computer Science (IJEECS), vol. 15, no. 2, pp. 956-961, 2019.

[11] N.B.A. Rahim, M.R. Islam, J.S. Mandeep, H. Dao, and S.O. Bashir, "Tropospheric scintillation prediction models for a high elevation angle based on measured data from a tropical region," Journal of Atmospheric and SolarTerrestrial Physics, vol. 105, pp. 91-96, 2013.

[12] N. B. A. Rahim, et al., "Comparison of tropospheric scintillation models on earth-space paths in tropical region," Research Journal of Applied Sciences, Engineering and Technology, vol. 4, no. 11, pp. 1616-1623, 2012.

[13] A. S. Madhuri, G. Immadi, and M. V. Narayana, "Estimation of cumulative distribution of scintillation effect on Ku-band frequencies for one of the tropical regions using various models," Journal of Engineering Science \& Technology Review, vol. 11, no. 1, pp. 151-155, 2018.

[14] ITU-R, "P.453-13 the radio refractive index : Its formula and refractivity data," International Telecommunication Union, 2017.

[15] J. S. Mandeep, A. C. C. Yee, M. Abdullah, and M. Tariqul, "Comparison and analysis of tropospheric scintillation models for Northern Malaysia," Acta Astronautica, vol. 69, no. 1-2, pp. 2-5, 2011.

[16] "Weather for Kuala Lumpur, Malaysia," Timeanddate.com, 2016. [Online]. Available: https://www.timeanddate.com/weather/malaysia/kuala-lumpur. [Accessed: 10-Dec-2018].

[17] I. E. Otung, "Prediction of tropospheric amplitude scintillation on a satellite link," IEEE Trans. Antennas Propag., vol. 44, no. 12, pp. 1600-1608, 1996.

[18] I.E. Otung, M.O. Al-Nuaimi, and B.G. Evans, "Extracting scintillations from satellite beacon propagation data," IEEE Trans. Antennas Propag., vol. 46, no. 10, pp. 1580-1581, 1998.

[19] A. Schuster, "On the investigation of hidden periodicities with application to a supposed 26 Day period of meteorological phenomena," J. Geophys. Res., vol. 3, no. 1, pp. 13-41, 1898.

[20] O. P. Banjo and E. Vilar, "Measurement and modeling of amplitude scintillations on low-elevation earth- space paths and impact on communication systems," IEEE Trans. Commun., vol. 34, no. 8, pp. 774-780, 1986.

[21] Y. Karasawa, M. Yamada, and J. E. Allnutt, "A new prediction method for tropospheric scintillation on earth-space paths," IEEE Trans. Antennas Propag., vol. 36, no. 11, pp. 1608-1614, 1988.

[22] M.M.J.L. Van De Kamp, J.K. Tervonen, E.T. Salonen, and J.P.V.P. Baptista, "Improved models for long-term prediction of tropospheric scintillation on slant paths," IEEE Trans. Antennas Propag., vol. 47, no. 2, pp. 249-260, 1999.

[23] H. Vasseur, "Prediction of tropospheric scintillation on satellite links from radiosonde data," IEEE Transactions on Antennas and Propagation, vol. 47, no. 2, pp. 293-301, 1999. 
[24] Herrera, J.T., Priore, M. and Mekonnen, D., Tropospheric Scintillation Signatures: Observations of the Possible Effect Thunderstorms have on GPS Signals, 2019.

[25] Pinho, A., Mota, S. and Rocha, A., A Quick Overview Of A New Scintillation Database, ICT Discoveries, vol. 2, no. 1, Nov. 2019.

\section{BIOGRAPHIES OF AUTHORS}
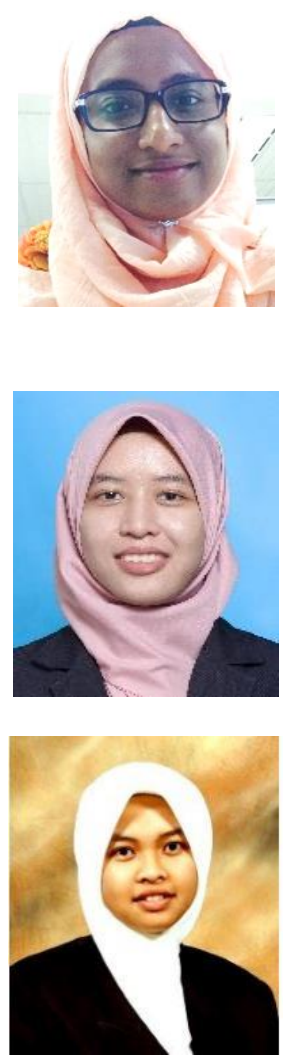

Nadirah Binti Abdul Rahim obtained the degrees B.Hons (Communications Engineering) in 2007 and Masters by research in Communications Engineering in 2013 from International Islamic University Malaysia (IIUM), Malaysia. She obtained her PhD degree in Systems Engineering at the School of Engineering, University of South Australia, Mawson Lakes, Adelaide, Australia in June 2018. She has previously worked as a Network Integration Engineer in a Malaysian telecommunication company called Sapura Secured Technologies. Her research interests include Satellite Communication Systems, Programming and Engineering Management. She is currently working as an Assistant Professor in International Islamic University Malaysia, under the Department of Electrical and Computer Engineering teaching Programming for Engineers in Undergraduate level. Nadirah is a member of IEEE, BEM and IET.

Hanis Nabilah Abd Mulop received the degree B.Hons (Communications Engineering) in 2019 from International Islamic University Malaysia (IIUM), Malaysia. She previously worked as an Internship Trainee at Malaysian Communications and Multimedia Commission (MCMC), a government agency for 3 months.

Khairayu Badron obtained her BEng (2006), Msc (2011) and Ph.D (2016) from International Islamic University Malaysia (IIUM). Previously, she worked as a Power Delivery Engineer at INTEL Corp, Bayan Lepas, Penang. She is currently one of the Assistant Professors at Faculty of Engineering, IIUM. She recently commenced her research areas in Radar and Radiometry research, quantifying propagation effects on microwave and millimetre wave links. Khairayu is a member of IEEE, IEM,BEM and MTSFB. She has published and co-authored more than 50 papers in International Journals as well as Conferences on subjects relating to wireless propagation, satellite communications and radar data processing. 